\title{
Challenges for research, policy and practice in the field of Roma health
}

\author{
Daniela Filakovska Bobakova ${ }^{1,2}$
}

Received: 26 April 2019/Accepted: 14 May 2019/Published online: 22 May 2019

(C) Swiss School of Public Health (SSPH+) 2019

In past centuries, our society developed rapidly, and improvement across all social determinants of health, including increasing quality of health care, led to better health status and higher life expectancy of the populations all over the world. These changes, however, were not equally transferred to the whole society, and marginalised groups, such as Roma (especially those living in marginalised communities), have not benefitted from them at the same level as majority populations. In recent decades interventions focused on "closing the gap" have been introduced but seemingly have not brought the expected extent of results when it comes to marginalised Roma communities (FRA 2018; Sandor et al. 2017). It would be rather unreasonable to expect, even with the best of will and intentions, that any measures or interventions could possibly reverse the effect of centuries of continuous and systematic exclusion and close the gap in a single generation. The causes of social exclusion are deeply rooted in a society, just as strategies related to adaptation to it are deeply rooted among marginalised Roma. The complexity of the issues related to the health status of marginalised Roma requires vision and multisectoral participatory solutions. Therefore, coordinated, systematic and continuous inclusion efforts involving target populations are seen by experts as the most feasible solution to the consequences of continuous and systematic exclusion. How to achieve the best possible results from such efforts is the "million-dollar question" that could and should be answered by high-quality research.

Regarding research and what its fundamental purpose should be: it should bring evidence, point out issues of societal relevance, raise awareness, support practice, evaluate the impact of actions, shape opinions and notions,

Daniela Filakovska Bobakova

daniela.filakovska@upjs.sk; bobakova.daniela@gmail.com

1 Department of Health Psychology, Faculty of Medicine, Pavol Jozef Safarik University, Kosice, Slovakia

2 Olomouc University Social Health Institute, Palacky University Olomouc, Olomouc, Czech Republic and last but not least help and support the shaping of policies. When it comes to research in the field of Roma health, substantial evidence has been brought by researchers from various fields of research (public health, epidemiology and social sciences) regarding health status, health disparities, health determinants, and the wider context in which Roma health is shaped (Cook et al. 2013; Belak et al. 2017; Madarasova Geckova et al. 2014). Related mechanisms have been outlined by several studies, but only scarce evidence exists on the effectiveness of such interventions (Belak et al. 2018; Lhussier et al. 2016; McFadden et al. 2018). We still need more relevant and demand-oriented research in this area to be able to provide evidence-based recommendations for policy and practice. The interconnection and cooperation between research, policy and practice should already be a matter of course, and recent trends in research aim to mirror not only the needs of policy and practice but also the needs of the target populations. And this is extremely important, because Roma living in marginalised communities are often seen as those who need to be helped by those who enter their communities with all kinds of projects (research, development, charity, etc.) but also often by the Roma themselves (Dunajeva 2018). We need to be aware of power relations when entering vulnerable communities, because they can prevent community members from speaking and outsiders from listening. Overcoming social hierarchies and earning the trust of community members is a challenge for any research trying to uncover what should be done and how it should be done, which lies right there in those communities embodied in needs and desires of the people living in them. Nevertheless, efforts focused and targeted solely on Roma themselves might be useless, whatever successful change they attempt to bring, as long as the attitudes of those privileged compared to the target population persist. If anti-Gypsyism, regardless of whether direct or subconscious, is present across societal structures, members of marginalised communities will constantly hit an invisible ceiling in their attempts to escape from the unfavourable situation and overcome complex consequences of social exclusion. It is therefore important to 
constantly point to the conscious and unconscious attitudes and related decisions of people, particularly employers, public figures, medical professionals, teachers and frontliners working in professions in direct contact with target populations, which affect the opportunities of Roma to emancipate themselves from a disadvantaged background (FRA 2018).

Thus, although we have already learned a lot, there are still challenges for research, policy and practice in the field of Roma health, such as anti-Gypsyism, inclusion, participation, intervention effectiveness, evaluation and resources, which need to be addressed.

\section{References}

Belak A, Madarasova Geckova A, van Dijk JP, Reijneveld SA (2017) Health-endangering everyday settings and practices in a rural segregated Roma settlement in Slovakia: a descriptive summary from an exploratory longitudinal case study. BMC Public Health 17:128. https://doi.org/10.1186/s12889-017-4029-x

Belak A, Madarasova Geckova A, van Dijk JP et al (2018) Why don't segregated Roma do more for their health? An explanatory framework from an ethnographic study in Slovakia. Int J Public Health 63:1123. https://doi.org/10.1007/s00038-018-1134-2

Cook B, Wane GF, Valentine A, Lessios A, Yeh E (2013) Revisiting the evidence on health and health care disparities among the
Roma: a systematic review 2003-2012. Int J Public Health 58(6):885-911. https://doi.org/10.1007/s00038-013-0518-6

Dunajeva J (2018) Power hierarchies between the researcher and informants. Crit Rom Stud 1(2):124-143. https://doi.org/10. 29098/crs.v1i2.3

European Union Agency for Fundamental Rights (FRA) (2018) A persisting concern: anti-Gypsyism as a barrier to Roma inclusion. Publications Office of the European Union, Luxembourg. https://doi.org/10.2811/752870

Lhussier M, Carr SM, Forster N (2016) A realist synthesis of the evidence on outreach programmes for health improvement of Traveller communities. J Public Health 38(2):125-132. https:// doi.org/10.1093/pubmed/fdv093

Madarasova Geckova A, Babinska I, Bobakova D, Dankulincova Veselska Z, Bosakova L, Kolarcik P, Jarcuska P, Pella D, Halanova M, Team HepaMeta (2014) Socioeconomic characteristics of the population living in Roma settlements and their association with health and health-related behaviour. Cent Eur J Public Health 22:S57-S64. https://doi.org/10.21101/cejph.a3903

McFadden A, Siebelt L, Gavine A, Atkin K, Bell K, Innes N et al (2018) Gypsy, Roma and Traveller access to and engagement with health services: a systematic review. Eur J Public Health 28(1):74-81. https://doi.org/10.1093/eurpub/ckx226

Sandor J, Kosa Z, Boruzs K et al (2017) The decade of Roma Inclusion: did it make a difference to health and use of health care services? Int J Public Health 62:803. https://doi.org/10. 1007/s00038-017-0954-9

Publisher's Note Springer Nature remains neutral with regard to jurisdictional claims in published maps and institutional affiliations. 